\title{
Por que ainda ler Paulo Freire?
}

\section{Maria Inês Marcondes}

Pontifícia Universidade Católica do Rio de Janeiro (PUC-Rio), Rio de Janeiro/RJ - Brasil

\section{Apresentação}

Paulo Feire, inegavelmente, é uma referência incontornável, por ser o educador latino-americano mais conhecido em diferentes partes do mundo. Suas obras são amplamente lidas nas principais universidades no Brasil e no exterior, nos grupos de educação de adultos, nos movimentos sociais de educação popular, nos movimentos de mulheres, negros, indígenas, em grupos de sindicalistas e em muitos outros espaços. A obra Pedagogia do oprimido, publicada ao final da década de 1960, faz 50 anos em 2018 e continua sendo um dos livros mais lidos pelos educadores comprometidos com a justiça social. Nessa obra, Freire divulgou conceitos como educação bancária, educação libertadora, conscientização, relação dialógica, que, hoje, são amplamente incorporadas por todos que se preocupam com uma educação crítica voltada para a transformação social.

Pela importância de Freire e pelo aniversário de 50 anos de publicação de Pedagogia do oprimido, a revista Educação on-line do PPGE- PUC/Rio apresenta, neste número, um Dossiê: Por que ainda ler Paulo Freire?, composto por quatro artigos e uma resenha.

O primeiro artigo se intitula Paulo Freire, a filosofia e a vida e é da autoria de Walter Omar Kohan. Nesse artigo, o autor, a partir de uma leitura proposta por M. Foucault, insere Paulo Freire numa tradição filosófica iniciada por Sócrates e os antigos cínicos, em que o problema central era a vida como "uma forma de ser e ao mesmo tempo como uma forma de ética e heroísmo" (FOUCAULT, 2011, p. 196). Como resultado, apresenta um Paulo Freire, cuja vida não pode ser separada de seu pensamento, e sua vida filosófica é, ela própria, sua principal força educadora.

$\mathrm{O}$ artigo conclui

que, para além da forma particular em que Paulo Freire viveu sua vida de herói filosófico, ele nos ajuda a pensar nas possibilidades de uma compreensão da filosofia em que ela não é tanto uma teoria ou sistema de pensamento quanto uma forma de afirmar a vida, em conexão muito próxima com a educação e a política, tanto que é muito difícil separar uma da outra. É nesse sentido específico que Paulo Freire tem sido um filósofo: não tanto pelas teorias ou sistemas nos quais ele buscou sustentar sua prática, nem sequer pela qualidade filosófica de suas teorias ou pensamento, mas pela forma com que fez de sua vida um problema filosófico e de sua filosofia uma questão existencial. (KOHAN, 2018) 
O segundo artigo intitula-se Freire y el Movimiento de Reconceptualización de los Estudios Curriculares en los Estados Unidos, da autoria de Daniel Johnson-Mardones. Segundo o autor, o texto "explora as relações entre as duas críticas contra a visão técnico-instrumental do currículo." Especificamente, o artigo enfoca a influência de Paulo Freire no movimento de reconceitualização do campo dos estudos curriculares nos Estados Unidos. Com base na revisão dos textos fundamentais do movimento reconceituação, ele mostra Paulo Freire, no momento do início da reconceitualização dos estudos curriculares nos Estados Unidos. Conceitos freireanos como conscientização, humanização, educação libertadora foram importantes para aqueles que começaram a pensar sobre um campo acadêmico além da concepção de Tyler, de um currículo conhecido como desenvolvimento curricular. A mesma intenção está presente na obra de Freire para rejeitar essa lógica, o currículo de Tyler, que chegara à América Latina, nos anos 1960, como nova linguagem e tecnologia educacional.

O autor conclui que "o campo de estudo reconceitualizado que surgiu desse movimento intelectual também foi internacionalizado desde o começo, e não somente por causa das influências europeias, mas também pelas latino-americanas". Em relação à questão atual sobre internacionalização, o autor ressalta o dilema que

quando os campos acadêmicos aspiram a se converter em conversas internacionais, entram em jogo relações desiguais que podem sempre se reproduzir. Nesse sentido, o autor defende que conceber um campo, como os estudos curriculares, como uma conversação internacional, lugar de encontros dialógicos, implica num esforço permanente de descolonização. Esse diálogo requer voz e silêncio, falar e escutar. A conversação de Freire, Greene e Pinar oferecem exemplos de como deve ser esse diálogo. (JOHNSON-MARDONES, 2018)

O terceiro artigo se intitula Paulo Freire e os Estudos Curriculares na América Latina e nos Estados Unidos, da autoria de Ivanilde Apoluceno de Oliveira e Tânia Regina Lobato dos Santos. O objetivo do artigo é analisar as contribuições do pensamento educacional de Paulo Freire aos estudos curriculares na América Latina e nos Estados Unidos, tendo por foco o currículo crítico. Consiste em recorte de uma pesquisa de campo, de abordagem qualitativa, concluída em 2016 e realizada pelos Programas de Pós-Graduação em Educação da Universidade do Estado do Pará Uepa e da Pontifícia Universidade Católica do Rio de Janeiro - PUC-Rio, por meio do Programa de Intercâmbio Interinstitucional Casadinho/Procad/MEC, com financiamento do CNPq e Capes. Entre os procedimentos metodológicos, constam o 
levantamento bibliográfico e documental e a entrevista semiestruturada. Entre os resultados, destacam-se as contribuições de Paulo Freire para os estudos curriculares nos Estados Unidos e na América Latina, onde se acrescenta o debate de uma pedagogia pós-colonialista de currículo e o processo de democratização escolar. No Brasil, destaca-se o movimento de reorientação curricular efetivado em secretarias municipais de Educação, em diversos estados brasileiros.

As autoras concluem que

- currículo em Paulo Freire apresenta uma dimensão emancipatória e crítica, englobando a política, a teoria e a prática e ações educacionais em uma visão críticotransformadora, considerando no contexto curricular a cultura escolar. Dessa forma, rompe a estrutura disciplinar e impositiva de valores, relacionando os saberes de forma interdisciplinar, interagindo os saberes experienciais de vida dos educandos com os saberes escolares, por meio do diálogo. (OLIVEIRA; SANTOS, 2018)

Paulo Freire faz críticas ao modelo escolar vigente bancário e destaca que, para mudar a cara da escola, há necessidade da reformulação curricular. Uma escola democrática e popular, capaz de possibilitar a participação dos diferentes segmentos da escola, necessita, entre outras questões, reorientar o currículo e investir na formação permanente dos professores.

O quarto artigo se intitula Alfabetização de adultos e os Movimentos de Educação e Cultura Popular nos anos 1960: terreno fértil para a construção do pensamento freireano e é da autoria de Renato Pontes. $O$ texto tem como objetivo apresentar algumas reflexões construídas no contexto de produção da educação popular no Brasil, nos anos 1960, e que representam base fundante para a elaboração de conceitos e práticas nesse campo, incluindo aí a parte mais densa do pensamento freireano, expressa na Pedagogia do oprimido. Para tanto, o artigo se concentra na contribuição dos movimentos de juventude católica, um grupo bastante representativo desse contexto, e nas práticas engendradas por eles no enfrentamento do grave e histórico problema do analfabetismo adulto no país. São apresentadas, ao final, três ideias-chave consideradas síntese das principais contribuições desse grupo, no período dos anos 1960, e que encontram eco na obra de Paulo Freire.

A geração de educadores populares dos anos 1960 ousou enfrentar as concepções de educação instituídas em sua época e criar caminhos para a experimentação de métodos e práticas que geraram importantes formulações para se pensar o sentido da educação. Essas formulações estão muitas vezes presentes nas nossas práticas e concepções de educação nos dias de atuais, sem que tenhamos consciência disso. $O$ artigo é extremamente atual, pois o contexto que vivemos hoje, Revista Educação Online, Rio de Janeiro, n. 29, set-dez 2018, p.86-89 
no Brasil, é igualmente desafiador e o legado deixado por essa história nos convoca a pensar novamente quais são as novas nuances do poder instituído na relação opressor e oprimido nas experiências educativas. Que novos sentidos assumem no nosso tempo palavras como: "conscientização", "política" e "participação social"? E, sobretudo, o que a educação tem a ver com tudo isso?

O dossiê também apresenta a resenha do livro $A$ casa e o mundo lá fora: cartas de Paulo Freire para Nathercinha, de Nathercia Lacerda, de autoria de Maria Inês Marcondes e Juliana Dias da Silva. O livro resenhado apresenta as transcrições e imagens das seis cartas que Nathercia recebeu de Paulo Freire, durante um período de três anos. São cartas datadas e apresentam notícias de Freire em sua passagem enquanto exilado pelo Chile e Estados Unidos. As cinco primeiras cartas foram enviadas no período de 1967-1969 do Chile. A última, no final de 1969, dos Estados Unidos. A menina Nathercia afirma não entender por que deixaram de se corresponder nesse mesmo ano. Segundo ela, as cartas demoravam a chegar e ela tinha que enviar para endereços e nomes diferentes, talvez para evitar que descobrissem que era para Freire que ela encaminhava. O conteúdo das cartas é muito interessante. Nas primeiras, Paulo Freire mata a curiosidade da sua prima sobre o país vizinho, fala sobre a neve e as diferenças entre Chile e o Brasil; já em outras cartas, deixa transparecer um pouco do seu sentimento em relação aos homens, fazendo um apelo a sua prima para que não deixasse desaparecer sua essência de criança.

Trata-se de um livro que pode interessar a adultos e crianças. Traz à tona partes de uma correspondência valiosa que não se perdeu no tempo. Nathercia foi cuidadosa, mesmo sem saber que seu primo, mais velho, se tornaria o maior educador do Brasil.

Os quartos artigos e a resenha nos mostram que temos ainda motivo suficiente para ler Paulo Freire. A atualidade da sua obra fica evidente nas reflexões e propostas que Freire nos trouxe há 50 anos e que permanecem oferecendo fundamentação para um trabalho crítico e emancipador.

Por que ainda ler Paulo Freire? A leitura do dossiê nos mostra as razões.

\section{Referências bibliográficas}

FOUCAULT, Michel. A coragem da verdade. São Paulo: WMF Martins Fontes, 2011. 